\title{
Effect of Transglutaminase on the Gelation of Heat-denatured Surimi
}

\author{
Nobuo Seki, Hisanori Nozawa, and Shaowei Ni \\ Laboratory of Food Biochemistry, Faculty of Fisheries, Hokkaido University, \\ Minato, Hakodate 041-8611, Japan
}

(Received March 6, 1998)

\begin{abstract}
Frozen walleye pollack surimi blocks were thawed and heated at $30^{\circ} \mathrm{C}$ for up to 120 min to induce thermal denaturation. The heat-treatment decreased an endogenous TGase and myofibrillar Ca-ATPase activities to $14 \%$ and $37 \%$ of the initial values, respectively. The surimi gel formability and setting response were almost completely lost. Although the addition of MTGase to the heat-denatured surimi completely recovered myosin cross-linking reaction, the gel strength and setting response were only partially recovered. In the presence of EGTA, an inhibitor of the endogenous TGase, the gel formability and setting response of the native surimi paste were remarkably reduced. However, these properties were completely recovered by the addition of MTGase together with EGTA. These results apparently demonstrate that the maximum gel strength of a final gel reflects the development of an elastic gel network which formed by a two-step heating procedure depending on a combination of thermal gelling ability of native myosin molecules and TGase reaction in the surimi paste.
\end{abstract}

Key words: surimi, setting, transglutaminase, myosin, gelation, walleye pollack

Surimi was originally developed as raw material for kamaboko that is produced taking advantage of heat-gelling ability possessed by the primary components of myofibril proteins. The kamaboko-type gels made from walleye pollack surimi are formed by treating surimi with $2-3 \% \mathrm{NaCl}$ and by a two-step heating procedure including setting prior to final cooking.

The thermally induced gelation is a multi-step process initiated from native myosin sol which involves denaturation, protein unfolding, aggregation, and gel network formation as an orderly fashion. ${ }^{1-8)}$ During the setting, myosin is denatured and aggregated, and simultaneously polymerized by a calcium dependent endogenous TGase* which is responsible for the setting phenomenon and enhance the surimi gelling properties in a great extent. ${ }^{9-13)}$ Thus, the final gel properties seem to be largely determined by a combination of thermal gelling ability of myosin and TGase reaction in the surimi sol. ${ }^{14-16)}$ It is therefore important to separate the process of thermally induced gelation from setting effect induced by TGase to understand the final properties of the two-step heating gel.

In this paper we report the effect of the addition of TGase to the heat-denatured surimi, which almost totally lacks gelling ability and setting response, on the recovery of these properties in order to clarify the important roles of TGase and native structure of myosin in the gelling process.

\section{Materials and Methods}

\section{Materials}

Frozen walleye pollack Theragra chalcogramma surimi (SA grade) containing $170 \mathrm{mg}$ protein $/ \mathrm{g}, 4 \%$ sorbitol, $4 \%$ sucrose, and $0.2 \%$ polyphosphates was obtained from Nippon Suisan Kaisha Ltd. This was cut into $250 \mathrm{~g}$ blocks while frozen, packaged in polyethylene bags, and stored at $-40^{\circ} \mathrm{C}$ until use. MTGase derived from the culture broth of a variant of Streptoverticillium mobaraense was supplied by Ajinomoto Co., Inc. ${ }^{17}$ The preparation used was reagent grade showing a single band on SDS-PAGE and the specific activity was determined as 260 unit $/ \mathrm{mg}$ by our hands. MDC was purchased from Sigma. EGTA was obtained from Dojindo Laboratories. All other chemicals were of guaranteed grade and were purchased from Wako Pure Chemical Industries.

\section{Preparation of Heat-denatured Surimi}

The frozen surimi block was thawed in running tap water and then $20 \mathrm{~g}$ portions were packed into vessels. They were incubated at $30^{\circ} \mathrm{C}$ for $0,20,40,60$, and $120 \mathrm{~min}$ and then immediately cooled in an ice bath. We used the 120 min-heated surimi as a heat-denatured surimi in this research.

\section{Preparation of Two-step Heating Gel}

The native and heat-denatured surimis were ground with $0.5 \mathrm{M} \mathrm{NaCl}, 5 \mathrm{mM} \mathrm{CaCl}_{2}$, and $20 \mathrm{mM}$ Tris- $\mathrm{HCl}(\mathrm{pH}$ 7.0) at a final concentration. The protein concentration of the ground surimi paste was adjusted to $100 \mathrm{mg} / \mathrm{g}$ by the addition of $20 \mathrm{~mm}$ Tris- $\mathrm{HCl}(\mathrm{pH} \mathrm{7.0)}$. The surimi paste was stuffed into cylindrical plastic vessels $(3.7 \mathrm{~cm}$ in diameter; $2.0 \mathrm{~cm}$ in height) and applied on a two-step heating procedure; it was preincubated (set) at $25^{\circ} \mathrm{C}$ for various times and then cooked at $90^{\circ} \mathrm{C}$ for $20 \mathrm{~min}$. The cooked gels were immediately chilled in an ice bath.

The protein concentration was determined by the biuret

\footnotetext{
* Abbreviations used: TGase, transglutaminase (EC 2.3.2.13); MTGase, microbial TGase; MDC, monodansylcadaverine; EGTA, ethyleneglycolbis(2-aminoethylether)tetraacetic acid; SDS-PAGE, sodium dodecylsulfate-polyacrylamide gel electrophoresis.
} 
method using bovine serum albumin as a standard. ${ }^{18)}$

\section{Rheological Measurement}

The cooled gel was kept at room temperature $\left(20-22^{\circ} \mathrm{C}\right)$ for $2 \mathrm{~h}$, then removed from the vessel, and applied to the measurements of breaking strength and strain by using a cylindrical plunger $(5 \mathrm{~mm}$ in diameter) on a rheometer (Rheoner RE 3305, Yamaden, Tokyo) at a stage speed of $30 \mathrm{~mm} / \mathrm{min}$.

For dynamic rheological measurement, Rheolograph Sol (Toyo Seiki Seisakusho, Tokyo) was used as described previously. ${ }^{16)}$ The salted surimi paste $(1.6 \mathrm{~g})$ was deaerated, then put into a cell, and the blade $\left(1 \times 0.05 \times 2.5 \mathrm{~cm}^{3}\right)$ was inserted into the center of the sol. The sample was subjected to $3 \mathrm{~Hz}$ sinusoidal shear oscillations with a constant amplitude (displacement, $\pm 100 \mu \mathrm{m}$ ). Values of the storage modulus, $\mathrm{G}^{\prime}$, the rigidity due to the elastic response of the sample, and loss modulus, $G^{\prime \prime}$, the rigidity due to viscous response of the sample, were recorded during programmed heating. The reproducibility of the data was confirmed by duplicate runs.

\section{Assay of Enzyme Activity}

TGase activity was measured according to the method of Araki and Seki. ${ }^{19)}$ The standard reaction mixture contained $2 \mathrm{mg} / \mathrm{m} /$ acetylated casein, $0.5 \mathrm{mM} \mathrm{MDC,} 5 \mathrm{mM}$ $\mathrm{CaCl}_{2}, 5 \mathrm{~mm}$ dithiothreitol, and $50 \mathrm{mM}$ Tris- $\mathrm{HCl}$ (pH 7.5). The reaction was started by the addition of TGase at $25^{\circ} \mathrm{C}$ and terminated by the addition of $5 \%$ trichloroacetic acid. One unit of the activity was defined as the amount of enzyme that catalyzed the incorporation of $1 \mathrm{nmol}$ MDC into acetylated casein for $1 \mathrm{~min}$ of the incubation. TGase activity in the surimi paste was measured by the method of Takeda and Seki. ${ }^{20)}$ The activity was expressed as an amount of MDC (nmol) incorporated to the surimi (g) per $\min$.

For Ca-ATPase measurement, $5 \mathrm{~g}$ of surimi was washed repeatedly 3 times with $0.1 \mathrm{M} \mathrm{KCl}-20 \mathrm{mM}$ Tris-maleate $(\mathrm{pH}$ $7.0)$ to remove additives. The reaction mixture contained $0.5 \mathrm{M} \mathrm{KCl}, 5 \mathrm{mM} \mathrm{CaCl}_{2}, 1 \mathrm{mM} \mathrm{ATP}, 0.2-0.4 \mathrm{mg} / \mathrm{m} l$ of the washed surimi, and $25 \mathrm{~mm}$ Tris-maleate $(\mathrm{pH} \mathrm{7.0)}$. The assay was carried out at $25^{\circ} \mathrm{C}$ and terminated by the addition of $5 \%$ perchloric acid. The activity was expressed as liberated inorganic phosphates ( $\mu \mathrm{mol})$ per min and $\mathrm{g}$ of surimi.

\section{$S D S-P A G E$}

Protein samples were solubilized according to the procedure described by Seki et al ${ }^{10)}$ The sample $(0.4 \mathrm{~g})$ was suspended in $7.5 \mathrm{ml}$ of SDS-urea solution containing $2 \%$ SDS, $2 \% \beta$-mercaptoethanol, $8 \mathrm{M}$ urea, and $50 \mathrm{~mm}$ Tris$\mathrm{HCl}\left(\mathrm{pH} 8.0\right.$ ), heated at $100^{\circ} \mathrm{C}$ for $2 \mathrm{~min}$, and stirred continuously for $24 \mathrm{~h}$ at room temperature. SDS-PAGE was performed by a modified Laemmli's method ${ }^{21)}$ using 3\% polyacrylamide- $0.5 \%$ agarose slab gel. ${ }^{20)}$ Gels were fixed and stained with $0.12 \%$ Coomassie brilliant blue R 250 in $10 \%$ glacial acetic acid and 50\% methanol.

\section{Results and Discussion}

\section{Thermal Deterioration of Surimi}

Small surimi blocks were heated in the water bath at $30^{\circ} \mathrm{C}$ for up to $120 \mathrm{~min}$. During the heat treatment, the
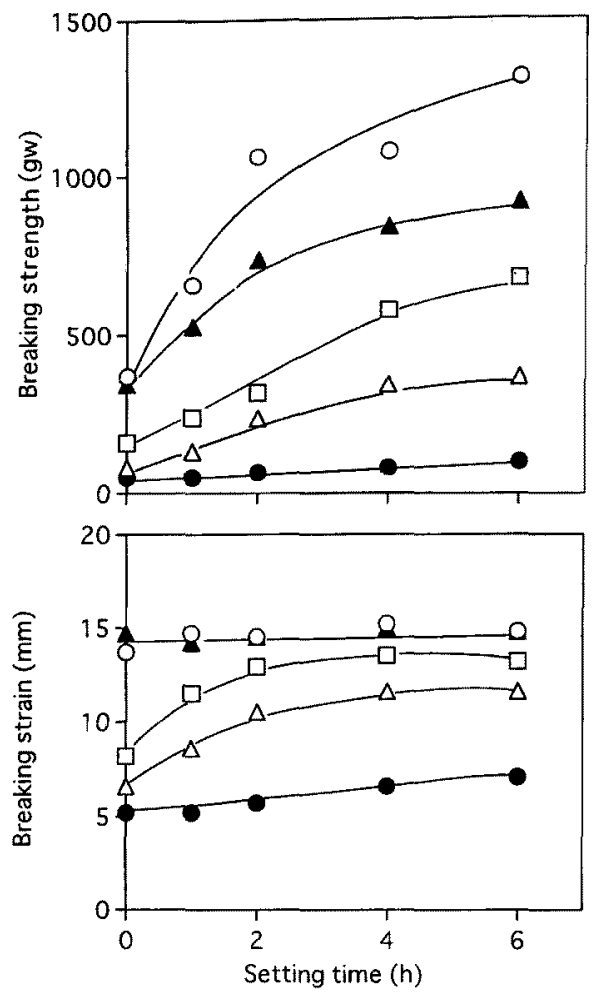

Fig. 1. Decrease in gel formability of salted surimi paste.

Walleye pollack surimi was previously heat-treated at $30^{\circ} \mathrm{C}$ for up to $120 \mathrm{~min}$. The salted pastes prepared from the heat-treated surimi were preincubated (set) at $25^{\circ} \mathrm{C}$ for various periods and then cooked at $90^{\circ} \mathrm{C}$ for $20 \mathrm{~min}$. The breaking strength and breaking strain of the cooked gels were plotted vs. setting time. $O$, Native surimi; $\boldsymbol{\Delta}$, surimi heat-treated for $20 \mathrm{~min}$; $\square$, surimi heat-treated for $40 \mathrm{~min} ; \Delta$, surimi heat-treated for $60 \mathrm{~min}$; $\bullet$, surimi heat-treated for $120 \mathrm{~min}$.

rate and extent of denaturation of the surimi were monitored by measuring the loss of gel formability together with the inactivation of myofibrillar Ca-ATPase and endogenous TGase. The surimi gels prepared from the native and heat-treated surimi were applied on a rheometer to measure their breaking strength and strain. The results are shown in Fig. 1. The breaking strength and strain of the gel decreased on increasing the heating time. After the heat-treatment for $120 \mathrm{~min}$, the gel forming ability of the surimi was almost lost together with the loss of setting response.

During the heat-treatment for up to $120 \mathrm{~min}$, SDSPAGE analysis showed that the protein composition of surimi was scarcely changed, suggesting that neither proteolysis nor cross-linking induced by TGase had occurred (compare 0 times in Fig.2, A and B). Wan et al. ${ }^{22)}$ reported that myosin heavy chain cross-linking did not occur in walleye pollack surimi at low salt. On the other hand, during the incubation of the salted paste prepared from the native surimi, myosin heavy chains were extensively crosslinked (Fig. 2A). The salted paste from heat-denatured surimi, however, showed little change in myosin heavy chain and other protein components during the incubation (Fig. 2B). These results suggested that TGase in the surimi was inactivated during the heat-treatment. We therefore estimated the inactivation rate of TGase in the surimi during 
A

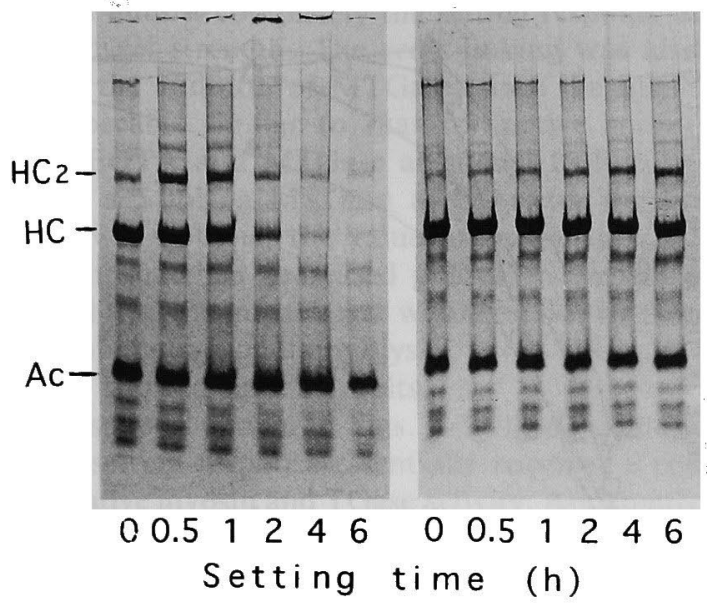

Fig. 2. Change in SDS-PAGE pattern of salted surimi paste during setting.

The salted pastes prepared from native surimi (A) and heat-denatured surimi which had previously been heated at $30^{\circ} \mathrm{C}$ for $120 \mathrm{~min}$ (B) were set at $25^{\circ} \mathrm{C}$ for up to $6 \mathrm{~h}$. Each $10 \mu \mathrm{g}$ of the surimi protein was applied to a $3 \%$ polyacrylamide- $0.5 \%$ agarose slab gel for SDSPAGE. HC, myosin heavy chain; $\mathrm{HC}_{2}$, myosin heavy chain dimer; Ac, actin.

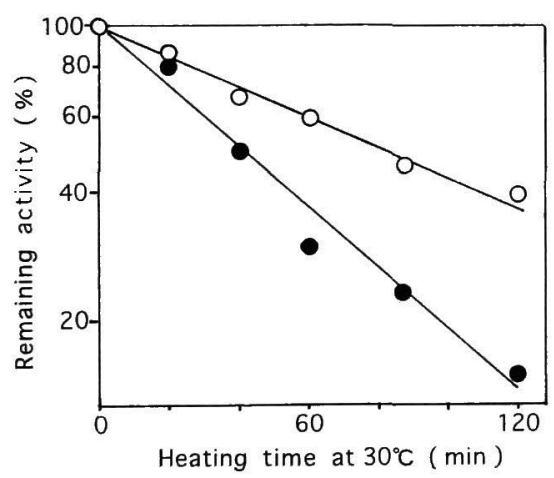

Fig. 3. Changes in TGase and Ca-ATPase activities of surimi during heat-treatment.

$\bullet$, TGase activity; $\bigcirc$, Ca-ATPase activity.

the heat-treatment as compared with that of Ca-ATPase activity as an index of myosin denaturation (Fig. 3).

Upon the heat-treatment for $120 \mathrm{~min}$, TGase activity in the surimi decreased to $14 \%$ of the initial value. The time course could be followed by plotting the natural logarithm of remaining activity vs. heating time, which gave a firstorder rate constant, $2.76 \times 10^{-4} \mathrm{~s}^{-1}$. Ca-ATPase activity was slowly decreased at a first-order rate constant of $1.39 \times 10^{-4} \mathrm{~s}^{-1}$; that is, approximately $37 \%$ of the initial activity remained even after 120 min-heating. These results clearly indicated that the inactivation of TGase and the loss of gel formability proceeded much faster than that of Ca-ATPase upon mild heat-treatment.

Effect of Added MTGase on the Gelation of Heat-denatured Surimi

In this section, we investigate the recovery of gel

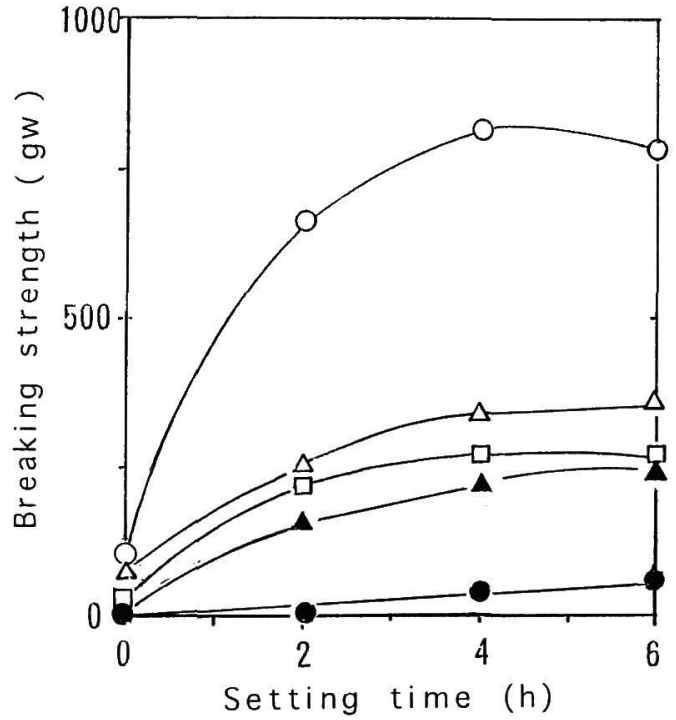

Fig. 4. Effect of added MTGase on the gelation of heat-denatured surimi.

The cooked gels were prepared by a two-step heating procedure from the salted pastes of native and heat-denatured surimi with or without added MTGase. The breaking strength of cooked gels was plotted vs. setting time. $\bigcirc$, Control, native surimi paste; $\bullet$, heatdenatured surimi paste; $\boldsymbol{\Delta}$, heat-denatured surimi paste with 0.5 unit/g MTGase; $\square$, heat-denatured surimi paste with 1.25 unit/g MTGase; $\triangle$, heat-denatured surimi paste with 5 unit/g MTGase.

formability of heat-denatured surimi by the addition of MTGase, because Seguro et al. ${ }^{23)}$ reported that MTGase could cross-link walleye pollack surimi proteins through $\varepsilon$ ( $\gamma$-glutamyl)lysine bonds and improved gel strength. Surimi was heat-treated at $30^{\circ} \mathrm{C}$ for $120 \mathrm{~min}$ prior to prepare the salted paste. MTGase was added to the heat-denatured surimi paste at various concentrations and then the surimi gel was prepared by a two-step heating procedure. The breaking strength of the surimi gel and setting response increased with an increase in the amount of added MTGase (Fig. 4). However, it was found that the breaking strength of the control gel from native surimi which contained 1.25 unit/g of endogenous TGase activity was 3 times higher than that of the corresponding MTGase-added surimi gel. Even the addition of excess MTGase (5 unit/g) gave an inferior gel as compared with the control gel. Thus, the gel formability and setting response were only partially recovered by the added MTGase to the heat-denatured surimi.

As in Fig. 2B, myosin heavy chains in the paste from heat-denatured surimi without MTGase were slightly polymerized by the remaining endogenous TGase during the setting. SDS-PAGE as shown in Fig. 5 revealed that the content of myosin heavy chain decreased and polymer content increased more rapidly with increasing the amount of added MTGase and in setting time. Apparent polymer content at the top of the acrylamide gel did not increase as polymerization proceeded after 4 and $2 \mathrm{~h}$ with addition of 2.5 and 5.0 unit/g of MTGase, respectively, because the highly polymerized forms were insoluble. It was noteworthy that the cross-linking of myosin heavy chains was completely recovered by the addition of $1.0 \mathrm{unit} / \mathrm{g}$ MTGase to the heat-denatured surimi which remained 0.21 unit/g en- 


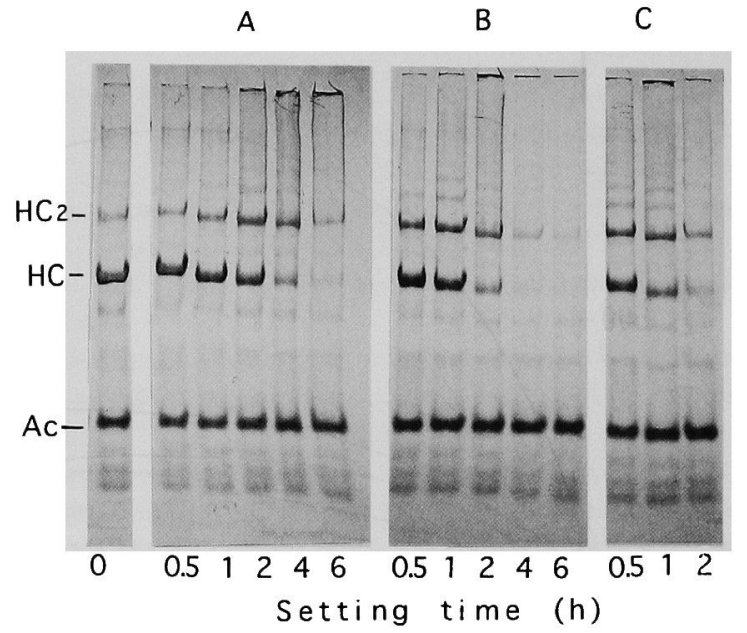

Fig. 5. Change in SDS-PAGE pattern of surimi paste containing added MTGase during setting.

The cooked gels as shown in Fig. 4 were analyzed by SDS-PAGE. A, heat-denatured surimi paste with added 1.0 unit/g MTGase; B, heat-denatured surimi paste with added 2.5 unit/g MTGase; C, heat-denatured surimi paste with added 5 unit/g MTGase; HC, myosin heavy chain; $\mathrm{HC}_{2}$, myosin heavy chain dimer; Ac, actin.

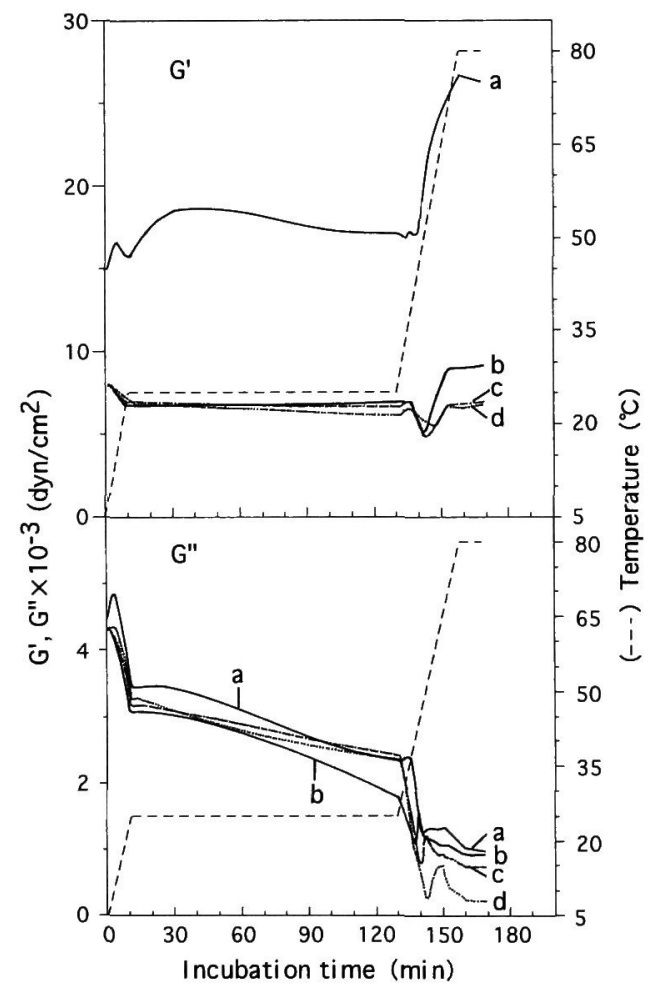

Fig. 6. Changes in storage modulus $\left(\mathrm{G}^{\prime}\right)$ and loss modulus $\left(\mathrm{G}^{\prime \prime}\right)$ of salted paste prepared from native and heat-denatured surimi with or without added MTGase during programmed heating.

The paste was heated from 5 to $80^{\circ} \mathrm{C}$ at heating rate of $2^{\circ} \mathrm{C} / \mathrm{min}$ including setting for $120 \mathrm{~min}$ at $25^{\circ} \mathrm{C}$. a, Control paste prepared from native surimi; $b$, heat-denatured surimi paste with added 5 unit/g MTGase; c, heat-denatured surimi paste with added 1.25 unit/g MTGase; d, heat-denatured surimi paste without MTGase. ----, temperature.



Fig. 7. Gelation of surimi paste in the presence of EGTA and added MTGase.

Surimi gel was prepared by a two-step heating procedure from the native surimi paste in the presence of EGTA $(5 \mathrm{~mm})$ and added MTGase. $\bigcirc$, Control without EGTA and MTGase; $\bullet$, without MTGase in the presence of EGTA; $\Delta$, with 0.5 unit/g MTGase in the presence of EGTA; $\square$, with 1.25 unit/g MTGase in the presence of EGTA; $\triangle$, with 5 unit/g MTGase in the presence of EGTA.

dogenous TGase activity (compare Fig. 2 with Fig. 5A).

Dynamic rheological properties of surimi paste were monitored during programmed heating from 5 to $80^{\circ} \mathrm{C}$ at heating rate of $2{ }^{\circ} \mathrm{C} / \mathrm{min}$ including setting at $25^{\circ} \mathrm{C}$ for 120 min (Fig. 6). $\mathrm{G}^{\prime}$ for native surimi paste showed a high value $\left(15,000 \mathrm{dyn} / \mathrm{cm}^{2}\right)$ at $5{ }^{\circ} \mathrm{C}$ and increased at the initial period of the setting. Although $\mathrm{G}^{\prime}$ and $\mathrm{G}^{\prime \prime}$ gradually decreased during the setting, a sharp increase in $\mathrm{G}^{\prime}$ to the maximum $\left(27,000 \mathrm{dyn} / \mathrm{cm}^{2}\right)$ and decrease in $\mathrm{G}^{\prime \prime}$ to the minimum during subsequent heating up to $80^{\circ} \mathrm{C}$ demonstrated the formation of an elastic gel network. In contrast, $\mathrm{G}^{\prime}$ of the paste from heat-denatured surimi with or without added MTGase was very low at about 7,000 $\mathrm{dyn} / \mathrm{cm}^{2}$ and did not increase throughout the setting. During the subsequent heating up to $80^{\circ} \mathrm{C}, \mathrm{G}^{\prime}$ increased slightly accompanying with a decrease in $\mathrm{G}^{\prime \prime}$. From all results (Figs. 4-6), we concluded that the denatured surimi could not develop an elastic matrix even with an excess of TGase.

\section{Requirement of TGase for Setting Response}

The absence of setting response in the heat-denatured surimi paste could result from the inactivation of endogenous TGase. However, an apparent partial recovery of setting response by the addition of MTGase to the heatdenatured surimi suggested that the presence of native myosin was also required for the complete recovery of the setting response. To determine if the native myosin structure was a factor, EGTA was added to the native surimi paste as an inhibitor of the endogenous TGase, ${ }^{14)}$ but not of MTGase. ${ }^{17)}$ The addition of EGTA dramatically reduced the setting response at $25^{\circ} \mathrm{C}$ (Fig. 7) and completely inhibited the myosin heavy chain cross-linking (data not 
shown). ${ }^{14)}$ In the presence of EGTA, the added MTGase recovered almost completely the setting response and the maximum gel strength. The cross-linking was also recovered by the addition of MTGase, since the SDS-PAGE pattern became similar to that for native surimi paste without EGTA and MTGase as shown in Fig. 2A. The effect of a 5 unit/g MTGase addition on the breaking strength was notable; the value increased rapidly to the maximum and then decreased gradually. Seguro et al. ${ }^{23)}$ suggested that the impairment would be due to excess formation of the $\varepsilon$-( $\gamma$-glutamyl)lysine cross-linkages. Lee et al. ${ }^{24)}$ also showed similar results.

The results as shown in Figs. 4-7 clearly demonstrated that the setting response essentially required a combination of native myosin and TGase activity. Apparently maximum gel strength is a response not only to development of the cross-linking, but also to development of an elastic matrix which is formed from native myosin and induced by heating.

Acknowledgments We thank Mr. Keiji Maruyama and Miss Kiyomi Matsumoto for their technical assistance. This research was supported in part by a Grant-in-Aid for Scientific Research from the Ministry of Education, Science, Sports, and Culture of Japan.

\section{References}

1) K. Iwata, K. Kanna, and M. Okada: Kamaboko formation of mackerel and red sea bream myosins. Nippon Suisan Gakkaishi, 43, 237 (1977).

2) K. Samejima, Y. Hashimoto, T. Yasui, and T. Fukazawa: Heat gelling properties of myosin, actin, actomyosin, and myosin subunits in a saline model system. J. Food Sci., 34, 242-245 (1969).

3) K. Samejima, M. Ishioroshi, and T. Yasui: Relative roles of the head and tail portions of the molecule in heat-induced gelation of myosin. J. Food Sci., 46, 1412-1418 (1981).

4) E. Niwa, K. Sato, R. Suzuki, T. Nakayama, and I. Hamada: Fluorometric study of setting properties of fish flesh sol. Nippon Suisan Gakkaishi, 47, 817-821 (1981).

5) T. Taguchi, H. Ishizaka, M. Tanaka, Y. Nagashima, and K. Amano: Protein-protein interaction of fish myosin fragments. $J$. Food Sci., 52, 1103-1104 (1987).

6) S. F. Noguchi: Dynamic viscoelastic changes of surimi during thermal gelation. Nippon Suisan Gakkaishi, 52, 1261-1270 (1986).

7) T. Sano, S. F. Noguchi, J. J. Matsumoto, and T. Tsuchiya: Thermal gelation characteristics of myosin subfragments. J. Food Sci., 55, 55-58, $70(1990)$

8) T. Sano, T. Ohno, H. Otsuka-Fuchino, J. J. Matsumoto, and T. Tsuchiya: Carp natural actomyosin: thermal denaturation mechanism. J. Food Sci., 59, 1002-1008 (1994).
9) T. Numakura, N. Seki, I. Kimura, K. Toyota, T. Fujita, K. Takama, and K. Arai: Cross-linking reaction of myosin in the fish paste during setting. Nippon Suisan Gakkaishi, 51, 1559-1565 (1985).

10) N. Seki, H. Uno, N. H. Lee, I. Kimura, K. Toyota, T. Fujita, and K. Arai: Transglutaminase activity in Alaska pollack muscle and surimi, and its reaction with myosin B. Nippon Suisan Gakkaishi, 56, 125-132 (1990).

11) I. Kimura, M. Sugimoto, K. Toyota, N. Seki, K. Arai, and T. Fujita: A study on the cross-linking reaction of myosin in kamaboko suwari gels. Nippon Suisan Gakkaishi, 57, 1389-1396 (1991).

12) G. G. Kamath, T. C. Lanier, E. A. Foegeding, and D. D. Hamann: Non-disulfide covalent cross-linking of myosin heavy chain in setting of Alaska pollock and Atlantic croaker surimi. J. Food Biochem., 26, 151-172 (1992).

13) N. Seki, C. Nakahara, H. Takeda, N. Maruyama, and H. Nozawa Dimerization site of carp myosin heavy chains by the endogenous transglutaminase. Fisheries Sci., 64, 314-319 (1998).

14) J. Wan, I. Kimura, M. Satake, and N. Seki: Effect of calcium ion concentration on the gelling properties and transglutaminase activity of walleye pollack surimi paste. Fisheries Sci., 60, 107-113 (1994).

15) H. G. Lee, T. C. Lanier, D. D. Hamann, and J. A. Knopp: Transglutaminase effects on low temperature gelation of fish protein sol. J. Food Sci., 62, 20-24 (1997).

16) S. Ni, H. Nozawa, and N. Seki: Effect of microbial transglutaminase on thermal gelation of carp actomyosin sol. Fisheries Sci., 64 434-438 (1998).

17) H. Ando, M. Adachi, K. Umeda, A. Matsuura, M. Nonaka, R. Uchio, H. Tanaka, and M. Motoki: Purification and characteristics of a novel transglutaminase derived from microorganisms. Agric. Biol. Chem., 53, 2613-2617 (1989).

18) A. G. Gornall, C. J. Bardawill, and M. M. David: Determination of serum proteins by means of biuret reaction. J. Biol. Chem., 177, 751-766 (1949).

19) H. Araki and N. Seki: Comparison of reactivity of transglutaminase to various fish actomyosins. Nippon Suisan Gakkaishi, 59, 711-716 (1993).

20) H. Takeda and N. Seki: Enzyme-catalyzed cross-linking and degradation of myosin heavy chain in walleye pollack surimi paste during setting. Fisheries Sci., 62, 462-467 (1996).

21) U. K. Laemmli: Cleavage of structural proteins during the assembly of the head of bacteriophage T4. Nature, 227, 680-685 (1970).

22) J. Wan, J. Miura, and N. Seki: Effects of monovalent cations on cross-linking of myosin in suwari gels from walleye pollack. Nippon Suisan Gakkaishi, 58, 583-590 (1992).

23) K. Seguro, Y. Kumazawa, T. Ohtsuka, S. Toiguchi, and M. Motoki: Microbial transglutaminase and $\varepsilon$-( $\gamma$-glutamyl) lysine crosslink effects on elastic properties of kamaboko gels. J. Food Sci, , 60, 305-311 (1995).

24) H. G. Lee, L. C. Lanier, D. D. Hamann, and J. A. Knopp: Transglutaminase effects on low temperature gelation of fish protein sols. J. Food Sci., 62, 20-24 (1997). 